\title{
The Reality of Women's Sport in Saudi Society
}

\author{
Hend Faye AL-shahrani \\ Department of Social Planning, Faculty of Social Services, Princess Nourah bint Abdulrahman University, Saudi Arabia
}

Received September 26, 2020; Revised November 11, 2020; Accepted December 22, 2020

\section{Cite This Paper in the following Citation Styles}

(a): [1] Hend Faye AL-shahrani, "The Reality of Women's Sport in Saudi Society," International Journal of Human Movement and Sports Sciences, Vol. 8, No. 6, pp. 525-533, 2020. DOI: 10.13189/saj.2020.080627.

(b): Hend Faye AL-shahrani (2020). The Reality of Women's Sport in Saudi Society. International Journal of Human Movement and Sports Sciences, 8(6), 525-533. DOI: 10.13189/saj.2020.080627.

Copyright $\mathrm{C} 2020$ by authors, all rights reserved. Authors agree that this article remains permanently open access under the terms of the Creative Commons Attribution License 4.0 International License

\begin{abstract}
Sports field is a strategic tool to achieve the 2030 vision. It is a substantial way to modify human behavior, self-discipline, refine the soul, and build the body. In addition, it plays a great role in building capital Social, strengthening the community fabric, and improving cohesion and social solidarity among individuals. The culture of sports in Saudi society, as a healthy lifestyle, is still absent. Therefore, it's indispensable to stimulate this concept in our society, to improve the quality of life and eliminate non-communicable diseases such as diabetes and obesity. This could be achieved by motivating and sensitizing individuals to the importance of sport to have a healthy lifestyle. This study aimed to determine the extent of sports practice among women in the Saudi society, by identifying the motives and obstacles among the women society in Saudi Arabia, moreover, seeking for suggestions and solutions to increase the culture of sports practice among women in Saudi society. To achieve this goal, a questionnaire has been applied to 432 Saudi women in Riyadh. The study was based on a descriptive approach. We conclude that Saudi women are keen to keep their fitness and increase their motivation for sports practice, increasing their motivation for exercising. The high cost of participating in the club is one of the obstacles that women face in society. Besides, the absence of school curricula for sport reduces Saudi women's awareness of the importance of practicing sport.
\end{abstract}

Keywords Sports, Practicing Sport, Saudi Women, Saudi Society

\section{Introduction}

Sports field is a principal socio-cultural phenomenon in the construction of Social society. Physical activity and practicing sport have an effective positive impact on raising individuals' general health in all age groups [1]. Physical sport has been scientifically proven to be the best sword to confront diseases that attack humans as they age, as regular exercise leads to an increase in life expectancy by $30 \%$. Karim [2] confirmed that sport is one of the factors, which helps to mitigate the pressures of individuals, as the exercise leads the person to feel pleased, acquire social relations, intimacy, and love. Besides, Al-Jerawi [3] confirmed that practicing sports activities has an effective role in creating a positive family atmosphere that paves the way for constructive discussions between sons and fathers. Sports are a kind of psychological relief, which promotes healthy development in general and especially emotional. By contributing to control and neuro balance in the body, it helps to restraint, patience, and control emotions [4].

Jifri [5] confirmed that sport is developing mental abilities by adding new information and experiences that contribute to solving problems, interaction, social participation, taking responsibility, respecting, and appreciating others. Given the importance of sports, the Kingdom's vision (2030) has been keen, for sports to be a culture of society and to achieve sports health awareness in the Community. Achieve vision goals by inculcating the concept of sport and its importance to everyone. Beside, enhance the athletic and fitness skills of visual, audio, and social media to apply the social value (a sound mind in a sound body) [6].

The culture of sports in Saudi society as a healthy lifestyle is still absent, especially for Saudi women. Al-Habdan [7] revealed the weakness of sports in the Kingdom and $(16 \%)$ of Saudi women is practicing sports for three days a week only. Fallatah, Seok Pyo and 
Alsaleh [8] revealed the importance of practicing sports for women. The reason for not practicing sports may be due to the social traditions and culture prevailing in society, making a dangerous impact on health; because the rate of obesity among Saudi women is the Second, immediately after Kuwait, among women, in the Gulf Cooperation Council [9]. Based on the above, it is necessary to strengthen the culture of exercise in society, to improve the quality of life and eliminate non-communicable diseases like diabetes and obesity. By motivating and sensitizing individuals to the importance of practicing sports for women for a better lifestyle.

Sport is a strategic tool to achieve the 2030 vision. It is a substantial way to modify human behavior, selfdiscipline, refine the soul, and build the body, as well as, building capital Social, strengthening the community fabric, and improving cohesion and social solidarity among individuals. The culture of sports in Saudi society as a healthy lifestyle is still absent [6]. So, it's indispensable to stimulate this concept in our society, to improve the quality of life and eliminate non-communicable diseases such as diabetes and obesity [10]. Motivating and sensitizing individuals to the importance of sport make it a lifestyle. Individuals' commitment to exercise as a lifestyle and an important part of their daily lives means better health, longer and more active lives, because they have incalculable health, psychological, and social benefits for the individual and society [11].

Therefore, the vision 2030 confirmed that the currently available opportunities for regular sport don't meet expectations, making the focus more on the vision, which should strengthen the rate of sports in Saudi society by $(40 \%)$ within (15) years instead of $(13 \%)$ now. As a goal of vision, these statistics lead to the importance of raising Saudi society's awareness of sports and linking it to health, by providing the right environment to be a firm behavior among all citizens in their society [12]. As a goal of vision, these statistics steer to the importance of raising Saudi society's awareness of sports and linking it to health by providing the right environment to be a firm behavior among all citizens in their society [13].

Sport plays a pivotal role in achieving the advancement of physical, psychological, social, and cognitive abilities for women [14]. Women are in desperate need of exercise to figure their daily lifestyle at all stages of their life, as they other than men are exposed to critical periods during their growing up as (puberty, menstruation, gestation, puerperal, and menopause) [15]. Therefore, the study focuses on identifying the obstacles that limit women's practicing sports in Saudi society.

Society has a tremendous role in promoting community participation in sports, as it is the key to sport for sustainable development. Through, an integrated society in which equality and social justice are achieved, and for generations to preserve their environment, sports can be used as a tool of social change for change, hope, and tolerance in society [16]. Also, Jifri [5] explained that the trends of Saudi Arabia's King Abdul Aziz University students toward physical activity were positive, as the health field came in the first order, and the psychological in the second-order, followed by the scientific field and the social sphere in the fourth and last order. However Chen [17] indicates that there are problems related to motivation and sports awareness among female students represented in cognitive deficiency of the importance of sport, and the incomprehensiveness in the features of sports activities, leading to a loss of interest in sports activities. Physical education programs and university sports activities help to foster motivation among female students to participate in sports activities [18]. Continuous reinforcement of sports activities helps to increase awareness of the importance of sports at University. Hence the courses on physical education, sports activities g and add facilities related to sports activities promote the active participation of female students. In addition, the growth of sports awareness and interest in sports enhances health in society in general [19].

The study of [20] aims to identify women's attitudes toward sports. The study included (860) women from the practices, non-practices of sports activities, and from frequenting on sports clubs. The results indicated a decrease in cultural awareness among women of the importance of practicing sports activity, leading to their reluctance to engage in sports activities, as the problem of overweight appears above the normal rate, which may increase the appearance of aging symptoms and a decrease in the body's resistance to diseases due to lack of movement. The study recommends the necessity of paying attention to the media, preparing media programs on women's sport, and correcting misconceptions and perceptions about women's sport. Moreover, Al-Ohali [21] indicated that the most severe obstacles to the sports are temperature and weather fluctuations such as dust, as they limit the practice of sport outside the home and no time for sports activities. The study recommends various women's sports activities, which are always free and regular, be carried out in universities.

The results of [22] study, which were applied to 127 university female students from Pakistan, indicated that $31.51 \%$ of university female students participating in sports activities are injured, and $22 \%$ from practicing physical sports activities, whereby overuse is the paramount cause of injuries with $52.8 \%$. The inner motivation for participation in sporting activities was enjoyment and enhancement knowledge, and the external motivation was the specific physical condition and organization. The prevalence of injuries associated with sports activities is severe among female students, and the use of inappropriate methods by female students in sports activities. Al-Jerawi [3] Showed that many obstacles hinder high school students' practicing such as (cultural, 
material, and administrative obstacles). The results indicated that the material obstacles came first, then administrative, followed by cultural obstacles. One such impediment is no closed and air-conditioned halls in the school and no locker rooms. Besides, to the lack of trainers and fitness qualities, sports activities are thought to be for weight reduction only. The [7] study, which was applied at (332) Saudi girls, indicated that practicing sport has positive effects in psychological terms, reducing their negative feeling of shame and depression, and removing their feeling of isolation and frustration. $75 \%$ of girls believe that their exercise contributed to recognizing their ability to control their behavior as action and reaction. Furthermore, exercise contributes to their self-confidence, responsibility, and decision-making. Moreover, it contributes to their health, as sports reduce cholesterol and blood sugar, improve their fitness, and help them regulate their sleep. In light of the above, this study aims to explore reality of women's sport in Saudi society, through the identification of the motives for practicing sports for Saudi women, Also, the obstacles to women's sports in Saudi society, finally, put proposals for activating sports for women in Saudi society.

\section{Materials and Methods}

\subsection{Participants}

There are (342) participants whose ages ranged from between $(20-50)$ years $(\mathrm{Y}=35.04, \mathrm{SD}=1.67)$. They all live in Riyadh, the capital of the Kingdom of Saudi Arabia, the sample-included girls from high school, university, and post-university. Researchers got the approval of this study from the scientific research department in Princess Nora bint Abdul Rahman University in Saudi Arabia. The study sample was randomly selected from the study community.

\subsection{The Questionnaire}

To gather data, the researcher in the current study, after reviewing the literature on women's sports in Saudi society, prepared a questionnaire of three main dimensions, including (33) paragraphs. The first dimension was aimed at identifying the motives for exercising for Saudi women in society, it included (12) sections. The second dimension recognizes the obstacles to women's exercise in Saudi society, it consists of (13) sections. The third dimension recognizes the proposals for activating women's sport in Saudi society, it consists of (12) sections. The questionnaire was given to faculty members to evaluate the dimensions and paragraphs, some modifications were made in the formulation of paragraphs. The five-point Likert scale (strongly agree - agree neutral - disagree - strongly disagree) has been used. Scores were distributed from 1 to 5 , one for "strongly disagree" and five for "strongly agree"; the Cronbach Alpha values for the three dimensions were calculated and were $0.70,0.83,0.85$, and the scale as a whole was 0.87

\subsection{Data Collection}

Researchers got the approval of this study from the scientific research department in Princess Nora bint Abdul Rahman University in Saudi Arabia. Data were collected in the form of an electronic questionnaire: The reality of women's sports in Saudi society.

\subsection{Data Analysis}

Data analysis and coding were performed using SPSS Statistics V18 to perform statistical analysis. Ratios, frequency, and standard deviation for study questions are calculated.

\section{Results}

First: the answer to the first question: What are the motives for practicing sports for Saudi women in society? To identify the motives for exercising Saudi women in society, repetitions, percentages, means, standard deviations, and ranking for the study sample responses were calculated on the first dimension of the motivation for the exercise of Saudi women in society, Table 1 explains these results: 
Table 1. Means, Standard Deviations, Percentage, and ranking on the Dimensions of the first field (Motives for practicing sports for Saudi women in society).

\begin{tabular}{|c|c|c|c|c|c|c|c|c|c|}
\hline $\begin{array}{l}\text { Items (Motives for } \\
\text { practicing sports) }\end{array}$ & $\begin{array}{c}\text { Repetition } \\
\text { (R) } \\
\text { Percentage } \\
(\%) \\
\end{array}$ & $\begin{array}{c}\text { Strongly } \\
\text { agree }\end{array}$ & Agree & Approved & Disagree & $\begin{array}{l}\text { Strongly } \\
\text { disagree }\end{array}$ & M & SD & Rank \\
\hline \multirow{2}{*}{ Getting fitness } & $\mathrm{R}$ & 168 & 164 & 9 & 1 & 0 & \multirow{2}{*}{4.46} & \multirow{2}{*}{0.56} & \multirow{2}{*}{1} \\
\hline & $\%$ & 49.1 & 48.0 & 2.60 & 0.30 & 0 & & & \\
\hline \multirow{2}{*}{ Getting agility } & $\mathrm{R}$ & 168 & 159 & 14 & 1 & 0 & \multirow{2}{*}{4.44} & \multirow{2}{*}{0.58} & \multirow{2}{*}{2} \\
\hline & $\%$ & 49.1 & 46.5 & 4.1 & 0.3 & 0 & & & \\
\hline \multirow{2}{*}{ Health preservation. } & $\mathrm{R}$ & 168 & 164 & 9 & 1 & 0 & \multirow{2}{*}{4.46} & \multirow{2}{*}{0.56} & \multirow{2}{*}{3} \\
\hline & $\%$ & 49.1 & 48.0 & 2.6 & 0.3 & 0 & & & \\
\hline \multirow{2}{*}{ Complacency } & $\mathrm{R}$ & 145 & 189 & 5 & 3 & 0 & \multirow{2}{*}{4.39} & \multirow{2}{*}{0.56} & \multirow{2}{*}{4} \\
\hline & $\%$ & 42.4 & 55.2 & 1.5 & 0.9 & 0 & & & \\
\hline \multirow{2}{*}{$\begin{array}{l}\text { Awareness of the } \\
\text { importance of exercising. }\end{array}$} & $\mathrm{R}$ & 107 & 202 & 28 & 4 & 1 & \multirow{2}{*}{4.20} & \multirow{2}{*}{0.56} & \multirow{2}{*}{5} \\
\hline & $\%$ & 31.3 & 59.0 & 8.2 & 1.2 & 0.3 & & & \\
\hline \multirow{2}{*}{ Investing leisure } & $\mathrm{R}$ & 114 & 172 & 34 & 18 & 4 & \multirow{2}{*}{4.09} & \multirow{2}{*}{0.86} & \multirow{2}{*}{6} \\
\hline & $\%$ & 33.3 & 50.3 & 9.9 & 5.3 & 1.2 & & & \\
\hline \multirow{2}{*}{$\begin{array}{l}\text { Having fun while } \\
\text { practicing. }\end{array}$} & $\mathrm{R}$ & 94 & 176 & 57 & 12 & 3 & \multirow{2}{*}{4.01} & \multirow{2}{*}{0.81} & \multirow{2}{*}{7} \\
\hline & $\%$ & 27.5 & 51.4 & 16.7 & 3.5 & 0.9 & & & \\
\hline \multirow{2}{*}{$\begin{array}{l}\text { Increasing the ability to } \\
\text { work and produce. }\end{array}$} & $\mathrm{R}$ & 73 & 165 & 74 & 23 & 7 & \multirow{2}{*}{3.80} & \multirow{2}{*}{0.92} & 8 \\
\hline & $\%$ & 21.3 & 48.3 & 21.7 & 6.7 & 2.0 & & & $\gamma$ \\
\hline Providing the opportunity & $\mathrm{R}$ & 56 & 103 & 92 & 69 & 23 & & & \\
\hline $\begin{array}{c}\text { international sporting } \\
\text { activities }\end{array}$ & $\%$ & 16.4 & 30.1 & 26.6 & 20.2 & 6.4 & 3.30 & 1.15 & 9 \\
\hline As requested by your & $\mathrm{R}$ & 24 & 119 & 118 & 67 & 14 & 321 & 097 & 10 \\
\hline doctor. & $\%$ & 7.0 & 34.8 & 34.5 & 19.6 & 4.1 & 3.21 & (1.51 & 10 \\
\hline Creating social & $\mathrm{R}$ & 27 & 91 & 113 & 81 & 30 & 301 & 108 & 11 \\
\hline relationships & $\%$ & 7.9 & 26.6 & 33.0 & 23.7 & 8.8 & 5.01 & 1.00 & 11 \\
\hline Bragoino & 78 & 78 & 138 & 62 & 42 & 22 & 239 & 115 & 12 \\
\hline Diaggily & 22.8 & 22.8 & 40.4 & 18.1 & 12.3 & 6.4 & 2.07 & 1.10 & 12 \\
\hline & & General ave & & & & & 3.80 & & 41 \\
\hline
\end{tabular}

Table 1 shows that the sample study agrees on the motives for practicing sports for Saudi women in society by an average (3.80 of 5.00). It is an average of the fourth category of the five-scale (3.41 to 4.20), which indicates an "agree" option of the study tool. The results show that the sample study "strongly agrees" with four of the motives for practicing sports for Saudi women in society, sections $(8,12,1,6)$ which were arranged in descending order according to the highly approved sample of the study.

Second: the answer to question 2: What are the obstacles to women's sports in Saudi society?

To identify the obstacles to women's sports in Saudi society, the results are calculated using repetitions, percentages, means, standard deviations, and ranking for the study sample responses to the second dimension paragraphs, obstacles to women's sports in Saudi society, Table 2 explains these results:

Table 2 shows that the sample study agrees on the obstacles to women's sports in Saudi society at an average (3.44 of 5.00), an average of the fourth category of the five-scale (3.41 to 4.20), which indicates an "agree" option of the study tool. The results in table 2 show that the sample study "strongly agrees" with one of the obstacles to women's sports in Saudi society, represented in section 11: "The high cost of participation in the club" by an average ( 4.40 out of 5 ). The results show that the sample of the study approved eight of the obstacles to women's sports in Saudi society, sections (13, 4, 9, 3, 6, 8, $12,5)$ that were arranged in descending order according to the sample of the study. 
Table 2. Means, Standard Deviations, Percentage, and ranking on the Dimensions of the second field (the obstacles to women's sports in Saudi society)

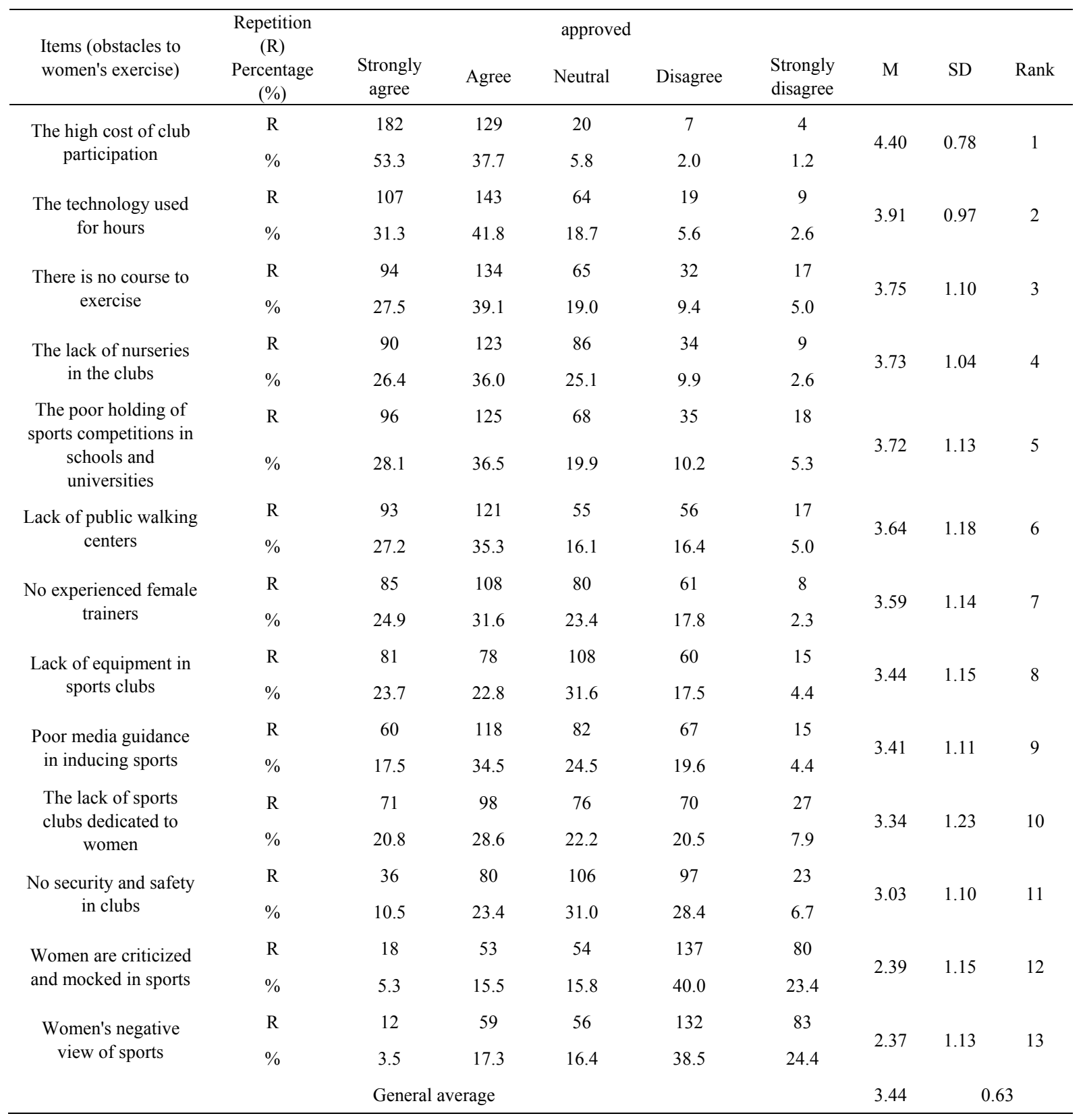


Third: the answer to question 3: What are the proposals and planning indicators for activating sports for women in Saudi society?

To identify proposals for activating sports for women in Saudi society, the results are calculated using frequencies, percentages, means, standard deviations, and ranking for the study sample responses to the third dimension paragraphs proposals for activating the exercise of women's sport in Saudi society, table 3 explains these results:

Table 3. Means, Standard Deviations, Percentage, and ranking on the Dimensions of the third field (proposals for activating sports for women in Saudi society).

\begin{tabular}{|c|c|c|c|c|c|c|c|c|c|}
\hline $\begin{array}{l}\text { Items (proposals for } \\
\text { activating women's sport) }\end{array}$ & $\begin{array}{c}\text { Repetition } \\
\text { (R) } \\
\text { Percentage } \\
(\%) \\
\end{array}$ & $\begin{array}{l}\text { Strongly } \\
\text { agree }\end{array}$ & Agree & Approve & disagree & $\begin{array}{l}\text { Strongly } \\
\text { disagree }\end{array}$ & M & SD & Rank \\
\hline \multirow{2}{*}{$\begin{array}{l}\text { Reduce the cost of } \\
\text { participating in sports clubs }\end{array}$} & $\mathrm{R}$ & 222 & 106 & 10 & 3 & 1 & \multirow{2}{*}{4.59} & \multirow{2}{*}{0.62} & \multirow{2}{*}{1} \\
\hline & $\%$ & 64.9 & 31.0 & 2.9 & 0.9 & 0.3 & & & \\
\hline \multirow{2}{*}{$\begin{array}{l}\text { Foster women about the } \\
\text { importance of exercising }\end{array}$} & $\mathbf{R}$ & 160 & 158 & 21 & 3 & 0 & \multirow{2}{*}{4.39} & \multirow{2}{*}{0.64} & \multirow{2}{*}{2} \\
\hline & $\%$ & 46.8 & 46.2 & 6.10 & 0.90 & 0 & & & \\
\hline \multirow{2}{*}{$\begin{array}{c}\text { Provide special sports clubs } \\
\text { for women in all } \\
\text { neighborhoods }\end{array}$} & $\mathbf{R}$ & 168 & 150 & 16 & 6 & 2 & \multirow{2}{*}{4.39} & \multirow{2}{*}{0.71} & \multirow{2}{*}{3} \\
\hline & $\%$ & 49.1 & 43.8 & 4.70 & 1.80 & 0.60 & & & \\
\hline \multirow{2}{*}{$\begin{array}{c}\text { Provide qualified cadres in } \\
\text { physical education }\end{array}$} & $\mathrm{R}$ & 169 & 143 & 22 & 8 & 0 & \multirow{2}{*}{4.38} & \multirow{2}{*}{0.71} & \multirow{2}{*}{4} \\
\hline & $\%$ & 49.4 & 41.9 & 6.4 & 2.3 & 0 & & & \\
\hline \multirow{2}{*}{$\begin{array}{c}\text { Equip sports facilities in girls' } \\
\text { schools (spacious halls, } \\
\text { equipment) }\end{array}$} & $\mathrm{R}$ & 171 & 141 & 21 & 7 & 2 & \multirow{2}{*}{4.38} & \multirow{2}{*}{0.74} & \multirow{2}{*}{5} \\
\hline & $\%$ & 50.0 & 41.3 & 6.1 & 2.0 & 0.6 & & & \\
\hline \multirow{2}{*}{$\begin{array}{l}\text { Promote cultural awareness of } \\
\text { the importance of exercising } \\
\text { through media programs }\end{array}$} & $\mathrm{R}$ & 143 & 170 & 23 & 5 & 1 & \multirow{2}{*}{4.31} & \multirow{2}{*}{0.68} & \multirow{2}{*}{6} \\
\hline & $\%$ & 41.8 & 49.4 & 6.7 & 1.5 & 0.3 & & & \\
\hline \multirow{2}{*}{$\begin{array}{l}\text { Choose sports activities to suit } \\
\text { the female nature }\end{array}$} & $\mathrm{R}$ & 135 & 168 & 32 & 4 & 3 & \multirow{2}{*}{4.25} & \multirow{2}{*}{0.74} & \multirow{2}{*}{7} \\
\hline & $\%$ & 39.5 & 49.0 & 9.4 & 1.2 & 0.9 & & & \\
\hline \multirow{2}{*}{$\begin{array}{l}\text { Provide nurseries in sports } \\
\text { clubs }\end{array}$} & $\mathrm{R}$ & 131 & 159 & 46 & 5 & 1 & \multirow{2}{*}{4.21} & \multirow{2}{*}{0.74} & \\
\hline & $\%$ & 38.3 & 4634 & 13.5 & 1.5 & 0.3 & & & 0 \\
\hline Add (physical fitness) & $\mathrm{R}$ & 147 & 137 & 40 & 10 & 8 & & & \\
\hline curricula & $\%$ & 43.0 & 40.1 & 11.7 & 2.9 & 2.3 & 4.10 & 0.91 & 9 \\
\hline Run sports competitions to & $\mathrm{R}$ & 134 & 149 & 40 & 15 & 4 & 15 & 097 & 10 \\
\hline motivate women & $\%$ & 39.2 & 43.5 & 11.7 & 4.4 & 1.2 & & & \\
\hline Orient the research and & $\mathrm{R}$ & 121 & 165 & 43 & 10 & 3 & 414 & 081 & 11 \\
\hline studies on sports activities & $\%$ & 35.4 & 48.2 & 12.6 & 2.9 & 0.9 & & & \\
\hline Allocate sports venues with & $\mathrm{R}$ & 118 & 127 & 69 & 22 & 6 & & & \\
\hline no music & $\%$ & 34.5 & 37.1 & 20.2 & 6.4 & 1.8 & 5.03 & & 12 \\
\hline & & General a & rage & & & & & 4.28 & 0.47 \\
\hline
\end{tabular}


Table 3 shows that the sample study "strongly agrees" with the proposals for activating sports for women in Saudi society by an average of 4.28 from 5.00 , which is in the fifth category of the five-scale category (4.21 to 5.00), which indicates a strongly-agree option for the study tool. The results show that the sample study "strongly agrees" with eight proposals for activating sports for women in Saudi society: sections $(4,10,1,9,8,12,3,5)$ which were arranged in descending order according to the "strongly agree" of the study.

\section{Discussion}

Sport is a strategic tool to achieve the 2030 vision. It is a substantial way to modify human behavior, selfdiscipline, refine the soul, and build the body. As well as, building capital Social, strengthening the community fabric, and improving cohesion and social solidarity among individuals. The culture of sports in Saudi society as a healthy lifestyle is still absent $[5,6]$. Therefore, it's indispensable to stimulate this concept in our society, to improve the quality of life and eliminate non-communicable diseases such as diabetes and obesity. By motivating and sensitizing individuals to the importance of sport, making it a lifestyle [10]. Hence, this study aimed to determine the extent of sports practice among women in the Saudi society, by identifying the motives and obstacles among the women society in Saudi Arabia. Moreover, it aimed to seek for suggestions and solutions to increase the culture of sports practice among women in Saudi society.

The first question results have shown many motives, as the eighth section, "getting fitness," was ranked first, explaining that Saudi women are keen to maintain their physical fitness to keep their active, making them more motivated to exercise. The twelfth section, "getting the agility," was ranked second, explaining that Saudi women are keen to maintain their agility to preserve their beauty, making them more motivated to exercise. The first section, "health preservation," was ranked third, explaining that Saudi women realize that sport reduces their weight and contributes to maintaining their health, making them more motivated to exercise. The sixth section, "complacency", was ranked fourth, explaining that Saudi women through practicing sports feel that they have achieved the desired benefit, making them feel more satisfied and more motivated to practice sport to achieve their self-satisfaction. The second section, "awareness of the importance of exercising," was ranked fifth, explaining that Saudi women's awareness of the importance of practicing sports increases their interest in practicing; therefore, this awareness represents an incentive for practicing sports. The ninth section, "the investment leisure," was ranked sixth, explaining that Saudi women are working to benefit from their leisure time in what is useful. Consequently, investing in leisure time is a motive for them to exercise sports. The third section, "having fun while exercising," was ranked seventh, explaining that Saudi women are changing their lifestyle and reducing routines, so having fun while practicing sports is a motive for them. The fifth section, "increasing capacity for work and production," was ranked eighth, explaining that Saudi women are working to strengthen their activity. By exercising, therefore, increased ability to act Production is a motive for sport. All these studies agreed with $[7,21,23$, 24].

Based on the second question about the obstacles to women's sport in Saudi society, the results indicated that there are many obstacles that Saudi women face in practicing sports, as the 11th section, "the cost of participating in the club", was ranked first. The thirteenth section, "technology for long hours" was ranked second, explaining that Saudi women practice sports on equipment that makes them fear the effects of this equipment on them, which hinders their practice of the sport. The fourth section, "no course to exercise," was ranked third, explaining that the absence of a course for practicing sports reduces Saudi women's awareness of the importance of sports, which hinders their practice of the sport. The ninth section, "the lack of nurseries in the clubs," was ranked fourth, explaining that the lack of nurseries in the clubs does not allow Saudi women to benefit from these nurseries to take care of their children while practicing sports, which hinders their practice of the sport. The third section, " the poor holding of sports competitions in schools and universities," was ranked fifth, explaining that poor holding sports competitions in schools and universities reduce Saudi women's enthusiasm for practicing sports, which hinders their practice of the sport. The sixth section, "lack of public walking centers in the districts", was ranked sixth, explaining that the lack of public walking centers in the districts does not allow Saudi women to benefit from this environment for sports, which hinders their practice of the sport. The eighth section, "no experienced female trainers" was ranked seventh, explaining that the lack of experienced trainers reduces the access of Saudi women to adequate training while practicing sports, which hinders their practice of the sport. The twelfth section, "lack of equipment in sports clubs," was ranked 8th, explaining that the lack of equipment in sports clubs does not enable Saudi women to practice sports activities that suit them, which hinders their practice of the sport. The second section, "poor media guidance in inducing sports ", was ranked 9th, explaining that the poor media guidance in inducing sports reduces Saudi women's knowledge of the importance of sports, which hinders their practice. The seventh section, "the lack of sports clubs dedicated for women," was ranked tenth, explaining that there is an interest in supporting women by creating an appropriate environment for them to practice, which doesn't hinder 
their practice of the sport. Finally, the tenth section, "the lack of security and safety in the clubs," was ranked eleventh, explaining that women's sports clubs are accredited according to the necessary safety standards, which doesn't hinder their practice of the sport. All these studies agreed with[3, 20, 24, 25].

Regarding the third question on proposals to activate sports for women in Saudi society, the proposals of the third dimension were as the following order: The fourth section, "reducing the costs of participating in sports clubs," was ranked first, explaining that reducing the costs of participating in sports clubs allows women to participate effectively in these clubs, which enables them to practice. The tenth section, "fostering women about the importance of exercising" was ranked second, explaining that sensitizing women about the importance of practicing sport enhances their awareness of the importance of practicing sports, which enables to them practice. The first section, "providing special sports clubs for women in all neighborhoods," was ranked third, explaining that providing special sports clubs for women in all neighborhoods allows them to easily access these clubs, thus enabling their practice of the sport. The ninth section, "Providing qualified cadres in physical education" was ranked fourth, explaining that providing qualified cadres in physical education provides Saudi women with access to adequate training and benefit from qualified trainers, which enables them to practice. The eighth section, "equipping sports facilities in girls' schools (spacious halls, equipment)" was ranked fifth, explaining that equipping sports facilities in girls' schools (spacious halls, equipment) enables them to benefit from this prepared environment, which enables to them practice. The second section, "spreading cultural awareness of the importance of sports through media programs," was ranked sixth, explaining that spreading cultural awareness of the importance of sports through media programs reinforces Saudi women's awareness of sports, which enables them to practice. The third section, "Choosing sports activities to suit the female nature," was ranked seventh, explaining that choosing sports suit female nature stimulates the initiative of Saudi women to practice sports, which enables them to practice. The fifth section, "providing nurseries in sports clubs." was ranked eighth, explaining that placing nurseries in sports clubs allows Saudi women to take care of their children on their behalf while practicing sports, which enables them to practice. The seventh section, "adding (physical fitness) curricula within the academic curricula," was ranked ninth, explaining that Saudi women are keen to maintain their fitness to keep their active, increasing their motivation for practicing sports. The second section, "running sports competitions to motivate women" was ranked tenth; explaining that running sports competitions to motivate women strengthens the encouragement of Saudi women to sports, which enables them to practice. The eleventh section, "orienting the research and studies on sports activities" was ranked eleventh, explaining that Orienting the research and studies on sports activities enhances the knowledge of the reality of women's sport in Saudi society and improves it, which enables them to practice. The sixth section, "allocating sports venues with no music", was ranked twelfth, explaining that allocating sports venues with no music increases the Saudi woman's sense of comfort while practicing sports, which enables them to practice. All these studies agreed with $[17,26]$

\section{Conclusions}

The paper reviewed the research results on the reality of women's sports in Saudi society. These measures were applied to a sample of the community in Riyadh, Saudi Arabia. The main contribution of this research is providing a deeper understanding of the motives behind practicing sports for Saudi women, as well as identifying the obstacles of practicing sport, then offering suggestions to activate practicing sports for Saudi women. Since this issue has not been given sufficient attention in the past at the level of Arab society, especially in Saudi Arabia, the study highlights the reality of women's sports in Saudi society, the government of Saudi society to address the obstacles facing women's exercise of sports. To reduce the costs of participating in women's sports clubs, provide an electronic application that identifies the venues and events of sports activities in various cities in the Kingdom. Build one-quarter sports groups (through social media groups), and play sports collectively in neighborhood parks (walking, running, and Cycling). Furthermore, provide special sport clubs for women in all neighborhoods; provide qualified cadres in women's physical education. Besides, equip sports facilities in girls' schools (large halls, equipment), promote cultural awareness of the importance of sports through media programs, and choose sports activities to suit the female nature.

We hope that this research results encourage officials to look at this indispensable issue in greater depth, to fully support Saudi women in what helps them practice sports within Saudi society, and reduce the obstacles that Saudi women face.

\section{Acknowledgments}

The Authors would like to thank the Center for Promising Research in Social Research and Women's Studies Deanship of Scientific Research at Princess Nourah bint Abdulrahman University, Kingdom of Saudi Arabia for funding this project in (1441 AH / 2019). 


\section{REFERENCES}

[1] A. Menevse, and M. E. Ablay, "An Investigation of the Attitudes of Sports Media towards Women's Sports," Universal Journal of Educational Research, vol. 7, no. 1, pp. 87-94, 2019.

[2] I. A. Karim, "A comparative study of the level of depression among female students, practicing and non-practicing sports activity in the College of Basic Education, University of Sulaymaniyah," Journal of Physical Education Sciences, vol. 7, no. 3, pp. 100-112, 2014.

[3] H. H. Al-Jerawi, "Barriers of sport activities practice among high school female student," King Saud University Master thesis unpublished, 2019.

[4] A. Zekioglu, and N. Kalkan, "Anatolian Cultural Heritage: Ancient Stadiums Related to Sport or Physical Culture?," Universal Journal of Educational Research, vol. 7, no. 1, pp. 106-110, 2019.

[5] A. Jifri, "Attitudes of King Abdul-Aziz University Students in Saudi Arabia towards Physical Activity" An-Najah University Journal for Research (Humanities), vol. 28, no. 8, pp. 1899-1922, 2013.

[6] M. Hvidt, "Saudi Arabia: Domestic factors underpin its sudden interest in sports," Videnscenter Om Det Moderne Mellemøsten, 2019.

[7] A. Al-Habdan, "A community study on the effects of exercise on girls: a study applied to the city of Riyadh.," Journal of Social Service, Egyptian Association of Social Workers, vol. 57, no. 2, pp. 1-21, 2017.

[8] B. A. Fallatah, H. Seok Pyo, and B. N. Alsaleh, "Recreational physical activity participation among women in Saudi Arabia," 2019.

[9] H. M. Al-Hazzaa, and M. A. AlMarzooqi, "Descriptive analysis of physical activity initiatives for health promotion in Saudi Arabia," Frontiers in public health, vol. 6, pp. 329, 2018 .

[10] N. Schulenkorf, and K. Siefken, "Managing sport-for-development and healthy lifestyles: The sport-for-health model," Sport Management Review, vol. 22, no. 1, pp. 96-107, 2019.

[11] B. Eigenschenk, A. Thomann, M. McClure, L. Davies, M. Gregory, U. Dettweiler, and E. Inglés, "Benefits of outdoor sports for society. A systematic literature review and reflections on evidence," International journal of environmental research and public health, vol. 16, no. 6, pp. 937,2019

[12] M. D. Al Ruwaili, "Females and sport in Saudi Arabia: An analysis of the relationship between sport, region, education, gender, and religion," 2020.

[13] H. M. Alshuwaikhat, and I. Mohammed, "Sustainability matters in national development visions-Evidence from Saudi Arabia's Vision for 2030," Sustainability, vol. 9, no. 3, pp. 408, 2017.

[14] L. Coleman, L. Cox, and D. Roker, "Girls and young women's participation in physical activity: psychological and social influences," Health education research, vol. 23, no. 4, pp. 633-647, 2008

[15] J. P. Borg-Stein, D. J. Fogelman, and K. E. Ackerman, "Exercise, sports participation, and musculoskeletal disorders of pregnancy and postpartum." pp. 413-422.

[16] W. Lemke, "The role of sport in achieving the sustainable development goals," UN Chronicle, vol. 53, no. 2, pp. 6-9, 2016.

[17] Y. Chen, "The investigation on motivation of female college students for sports activities participation and the countermeasure on sport consciousness cultivation."

[18] E. Al-Eisa, A. Al-Rushud, A. Alghadir, S. Anwer, B. Al-Harbi, N. Al-Sughaier, N. Al-Yoseef, R. Al-Otaibi, and H. A. Al-Muhaysin, "Effect of motivation by "Instagram" on adherence to physical activity among female college students," BioMed research international, vol. 2016, 2016.

[19] R. L. Jones, R. Harris, and A. Miles, "Mentoring in sports coaching: A review of the literature," Physical Education and Sport Pedagogy, vol. 14, no. 3, pp. 267-284, 2009.

[20] I. S. A. M. Ghazanfar, "Study women's attitudes towards sports recreation," Department of Sports Administration, Benha University - College of Physical Education -, Unpublished, 2005.

[21] H. H. Al-Ohali, "Attitudes of university students towards participation in community sport in Saudi society," King Saud University, unpublished 2019

[22] A. R. Memon, B. Ali, A. U. R. Memon, I. Ahmed, and J. Feroz, "Motivation and factors affecting sports participation: a cross-sectional study on female medical students in Pakistan," JPMA. The Journal of the Pakistan Medical Association, vol. 68, no. 9, pp. 1327-1333, 2018.

[23] M. A.-H. Ahmed, "A comparative study in the quality of life between practitioners and non-practicing sports for students of Karbala University colleges for the academic year," Journal of Physical Education Sciences, vol. 5, no. 3, pp. $1-18,2012$.

[24] J. F. M. Atoum, "Social class and its relationship to the trend towards sports in female schools in Jerash governorate," Reading and Knowledge Journal, vol. 179, pp. 199-220, 2018.

[25] M. Nawasiriyah, "Women's Attitudes Toward Practicing Sports Activity," Challenge Journal, Al-Arabi Bin Mahidi University, vol. 9, pp. 125-142, 2016.

[26] M. Carroll, and C. Little, "Barriers to women's sports participation in Saudi Arabia." 